\title{
DEVELOPING A RISK MANAGEMENT INDEX TO MEASURES THE CONTRIBUTION IN DISASTER RISK REDUCTION FOR LATINAMERICAN COUNTRIES
}

\author{
Claudio Garuti ${ }^{1}$, CarmenPaz Castro ${ }^{2}$, Fabiola Zamora, Vanessa Rugiero \\ ${ }^{1}$ Claudio Garuti \\ Fulcrum Ingeniería Ltda. \\ Ingenieria en Toma de Decisiones \\ claudiogaruti@fulcrum.cl \\ ${ }^{2}$ Carmen Paz Castro \\ Universidad de Chile \\ Facultad de Arquitectura y Urbanismo, Dpto. de Geografía \\ cpcastro@uchilefau.cl
}

\begin{abstract}
The aim of this work is to create a management index to measure how the Government Institutions are dealing with natural disasters, and prove it in six Latin-American Countries as case of study. This work was asked by United Nations in order to measure in a systemic way the real actions of Governments in disaster management, beyond legal paper regulations and normative.
\end{abstract}

Keywords: Disaster Management, AHP, Index of Measurement for Natural Risks Management (RMI).

\section{Introduction}

This work was asked by United Nations and is about building a global management index to measure the Government actions to reducing risks in front of natural disaster in Latin-American Countries. And it was carry on by Universidad de Chile Department of Geography and Fulcrum Ingenieria.

The index was call IGR (Indice de Gestion del Riesgo), or Risks Management Index (RMI in English), for natural disasters.

This kind of index has been built before only in financial terms (only for monetary criteria). This time, the index was built for more complex situation, considering all kind of information quantitative and qualitative criteria, some example criteria are: disaster mapping production, quality of the Institutions regulations, quality of data base disaster maps, quality of existing legal frame, reconstruction in forbidden areas, etc..., and applied in 6 Countries in LA (Mexico, Nicaragua, Honduras, Colombia, Argentina and Chile), with expert of disasters (seniors) of those six Countries (geographers, architects, engineers, medical doctor and lawyer), using the AHP metric building engine in its absolute measurement mode to build the index.

\section{The Works Hypothesis:}

- The presence of a regulatory frame in natural risks and a referenced land management do not assure its application in the necessary process of reducing disaster risks.

- The land risks management regulations do not assure by itself their accomplishment, producing conflicts in the using of the land, creating new scenarios of disasters 
- In LatinAmerican Countries the natural risks management is changing for worse, due to the absence of clear responsible in the risks management assessment among the many Organizations, Agencies and Offices, with null or deficient regulatory tools for the necessary coordination inter-land and inter-offices, presenting a strong case of lack of empowerment and burocracy.

\section{The Procedure:}

To achieve the proposed objective, the work team gathered a large collection of data for the six selected Countries (in site), and then categorizing the data to make it homogenous and useful for the AHP model. At the same time, an AHP model (in the absolute measure mode), was been produced for all the relevant criteria related to the risks management index or RMI, with about 10 experts (seniors) that belong to the same six Countries.

Next figure shows the AHP model that builds the metric for the RMI index:

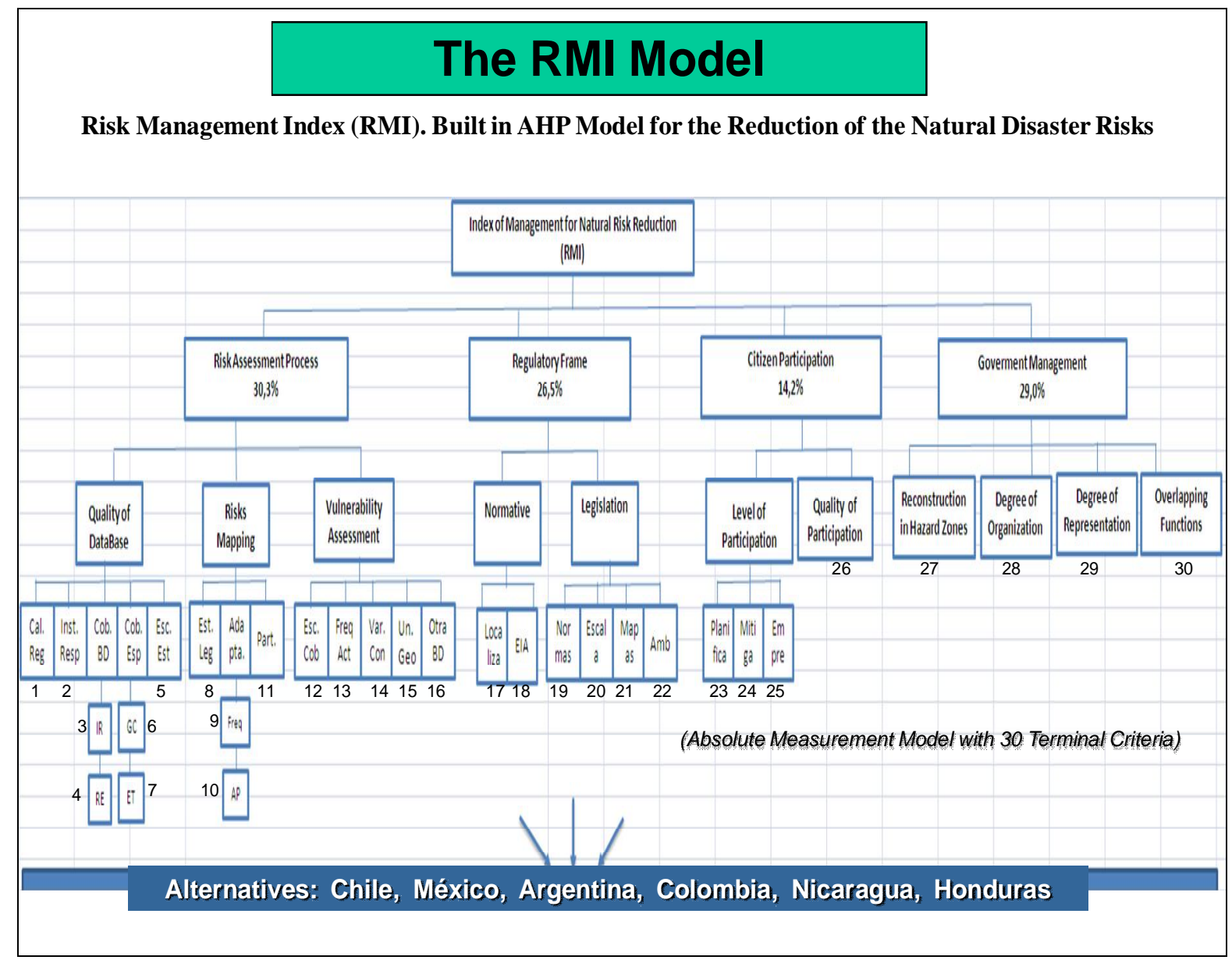

The selection of Countries was made considering different developing level of the Countries in order to have a broad vision of the Region, using the Amadeo classification (2003), which considers 3 variables: Level of Production, Equity of distribution, and the degree of International Insertion.

The process produced four categorization groups: 
First group: Countries with medium to high incomes that present relative good behavior for all three variables. In this case Chile was selected as a representative Country.

Second Group: Countries with medium to high incomes that present a relative regular behavior for the variables. In this case the representative selected country was Mexico.

Third Group: In this case we have two groups: Countries with that present a relative regular behavior for the variables but with a clear trend to diminish in one or all three variables. In this case the representative selected country was Argentina, and for Countries with medium to low income was selected Colombia.

the Fourth group also with two categories, the group with medium to low income but with regular behavior in at least one variable, in this case was selected Nicaragua, and Countries that present null or negative performance for all variables, in this case was selected Honduras.

Also, it was built a second AHP model to measure the real level of implementation of the government actions based more on data than legal paper regulations and normative (considering more what are they really doing than what are they saying that are doing). This second model is applied as a "modulator" of the main model, weighting the outcome obtained with the main model by the degree of real implementation of legal procedures present in the Country`s territorial normative.

\section{The Results:}

The AHP model was applied over the six selected countries, some of the main results obtained were:

- Cardinal ranking of the countries and the gap between each other.

- Gap assessment between the alternative evaluations in one given criterion compared with the local criterion threshold.

- Global acceptability level (global threshold), that defines which alternative is good, sufficient or bad regarding to the IGR index for the assessed Country.

- Sensitivity of the IGR index, performing a sensitivity analysis of the results, important to realize in what criteria and for how much the IGR index is sensitive. This last information become very useful for the resource allocation process, answering the question of where allocate the money and in what quantity to produce the maximum positive change for reducing risks in disaster management.

The results should be published by the United Nations Disaster Committee during 2011, and should be presented and implemented in the rest of Latin American Countries during 2012.

\section{REFERENCES}

Toma De Decisiones En Escenarios Complejos, Garuti C. Escudey M, 2005. Editorial Universidad de Santiago.

Papers:

When Close Really Mean Close". Garuti C. 2007. International Symposium of AHP (ISAHPIX,2007), Viña del Mar, Chile. 
IRG \& USAID/OFDA. 2008. Time to Pass the Baton. Disaster Risk Reduction from the Perspective of Environmental Management, Land Use Management, Finance and Public Investment. Juan Pablo Sarmiento Ed., Printed by Editorama S.A. San José C.R.

Mc Donald y Otava (2001)

UNITED NATIONS, 2009. Global Assesment Report on Disaster Risk Reduction. Risk and Poverty in a Changing Climate. Green Ink, UK.

UNIVERSIDAD NACIONAL DE COLOMBIA / IDB. 2007. Final Report of the Program for America. Summary Report. Cardona, O.D. Ed. Washington, D.C.

NACIONES UNIDAS. ASAMBLEA GENERAL. 2005. Informe de la Conferencia Mundial sobre la Reducción de los Desastres. Marco de Acción de Hyogo. In líne at: http://www.unisdr.org/eng/hfa/docs/final-report-wcdr-spanish.pdf [15] 